\title{
Role plays a teaching strategy for dental students: An institutional study
}

\author{
Samer Kasabah ${ }^{1, *}$, P. Sridhar Reddy ${ }^{1}$, Bina Kashyap ${ }^{2}$ \\ ${ }^{1}$ Department of Oral and Maxillofacial Surgery, Buraydah Private Dental College, Buraydah, Saudi Arabia \\ ${ }^{2}$ Department of Oral Pathology, Buraydah Private Dental College, Buraydah, Saudi Arabia
}

\section{A R T I C LE I N F O}

\section{Article history:}

Received 15 June 2016

Received in revised form

13 August 2016

Accepted 15 August 2016

\section{Keywords:}

Didactic

Dental

Learning

Teaching

Role play

\begin{abstract}
A B S T R A C T
This study employed to explore the outcome and benefits of role play as a teaching methodology for teaching dental subjects to the dental students. The experimental study group included 40 students (Group A and Group B) of the same level in Buraydah Private Dental College, Saudi Arabia. Students in the group A were taught through didactic lectures, while those in group B were taught using role play method. At the end of the course, we compared the outcome of theoretical knowledge before, after and one month after teaching. All the data were statistically evaluated using Graph Pad Prism software. The result obtained in pretest, posttest and surprise test were statistically significant. The role play method showed significantly better results compared to the didactic lectures $(\mathrm{p}<0.05)$. The role play showed $75 \%$ of result compared to didactic lectures $(60 \%)$. Retention of knowledge was also statistically significant among the groups. Role Play is an important and alternative method of teaching dental students. In addition, when the course is discussion based and asynchronous, it leaves time for student's to be reflective, which is a particular benefit of this role playing teaching method.
\end{abstract}

(C) 2016 The Authors. Published by IASE. This is an open access article under the CC BY-NC-ND license (http://creativecommons.org/licenses/by-nc-nd/4.0/).

\section{Introduction}

Education is one of the essential factors of development of human being. It enriches people's understanding, awareness, knowledge, physicality and mental maturity so as to raise the productivity and creativity to promote scientific advances. Education is achieved through active learning, which is increasingly acknowledged as a path of involvement, motivation and responsibility by the learners and the facilitators. In higher education system, the student's satisfaction and engagement has always been the prime feature of focus, which made the teachers/tutors/lecturers/facilitators or supervisors to perform various ways to ensure that they meet the expectations of students well for their workplace and future (Yardley-Matwiejczuk, 1997).

Teaching and learning goes side by side which encourages students to learn, attain knowledge and perform skills. Learning process can be passive or active. Passive learning is being followed worldwide through many years where teacher speaks and the

\footnotetext{
* Corresponding Author.

Email Address: skasabah@gamil.com (S. Kasabah)

http://dx.doi.org/10.21833/ijaas.2016.08.006

2313-626X/@ 2016 The Authors. Published by IASE.

This is an open access article under the CC BY-NC-ND license

(http://creativecommons.org/licenses/by-nc-nd/4.0/)
}

student listens, hence providing one way communication. Most of the undergraduate courses in higher education use this method of teaching i.e. lecture based classes. This type of transmission of knowledge is useful in just remembering the facts but is ineffective in producing high level content and necessary professional skills (Chalakh, 2015).

The interaction during teaching should provide cater for the academic and personal development of student, which is achieved through active learning. Active learning means learner centered learning where it is important for tutors to be alert towards teaching methods in which students enjoy to increase their involvement for better and effective learning (Yardley-Matwiejczuk, 1997). Role play is an effective pedagogical method of active teaching strategy that offers several way of strengthening interaction so as to arouse interests of learners and make language acquisition impressive. Problem based learning, use of concept maps, small group discussions are the other methods of active learning. Several academic disciplines such as medicine, nursing, history, dentistry, law etc. use role play as a method of teaching. Rao and Stupans (2012) reported positive response of students learning through the role play and concluded that role play provides an opportunity to get a deeper understanding of a subject and stimulates further interest in the subject. 
Role play is defined as "a learning activity in which participants act out a set of defined role behaviors or position with a view to acquiring desired experiences. (Agboola Sogunro, 2004) Yardley-Matwiejczuk (1997) describes it as activities where participants are involved in "as if" situations, by way of simulated actions and circumstances (Westrup and Planander, 2013). Role plays activities help introduce students to "real world" situations with positive attitudes and feelings. It provides a safe venue for expressing personal and sometimes unpopular attitudes and opinions, where majority of students enjoy these activities and become more inspired learners (Chalakh, 2015).

Role plays differ from other case studies in the imminence of the experience. This also provides opportunities for learning in the affective domain where emotions and values are involved as well as in the interpersonal skills, communication skills, and knowledge domain and cognitive domain where experiences are analyzed (Nickerson, 2007). Dentistry and Medical branches of health sciences deals with various, vast and challenging medical and dental case problems. As these subjects are considered very difficult and complex for the undergraduate level, a new teaching methodology i.e., role play, has been adopted for the better understanding of the subject. Hence, we authors have undertaken this study to evaluate the dental students studying the Cardio-Pulmonary Resuscitation subject, by the use of role play teaching procedure so as to assess student satisfaction, learning outcomes and retention of acquired knowledge.

\section{Materials and methods}

A simple randomized comparative observational study was conducted in the Department of Oral and Maxillofacial Surgery, Buraydah Private Dental College, Saudi Arabia. 40 students were selected for the teaching of CPR subject through the didactic method and through the role play lectures. Students were divided into 2 groups, Group A and Group B with 20 students in each.

Group B 20 students were subdivided into 4 groups of 5 students in each. Scenario was given to each subgroup. Before giving the topics a pretest (25 marks) was conducted for both the groups and the assessment was done. Group B students were given a time for preparing role play and after 2 - 3 hours students were asked to play the role play. At the same time the same topic was taught through lecture to group dental students. After completion of teaching a post test (25 marks) was conducted. Also to check the retention of the topic, a surprise objective questionnaire test (25 marks) was conducted after 30 days.

The average learning gain, relative learning gain and class average normalized gain (g) as per Hake Criteria was calculated for both the types of teaching methods. The scores of all the tests were considered for calculation of the result. The data of the pretest, posttest and surprise test evaluation assessment marks obtained by both the groups were tabulated and put for the statistical analysis. The data were put and processed for statistical validations by Graph pad Prism software for the one way ANOVA and unpaired' test.

\section{Result}

The average score of the students through role play and didactic lectures are presented in Table 1.

Table 1: Average marks scored by the groups through role paly and didactic lectures

\begin{tabular}{|c|c|c|c|c|}
\hline Interval of marks & Role play & $\%$ & Didactic & $\%$ \\
\hline $0-5$ & 0 & 0 & 2 & 10 \\
\hline $5-10$ & 3 & 15 & 2 & 10 \\
\hline $10-15$ & 2 & 10 & 4 & 20 \\
\hline $15-20$ & 8 & 40 & 8 & 40 \\
\hline $20-25$ & 7 & 35 & 4 & 20 \\
\hline Total & 20 & 100 & 20 & 100 \\
\hline
\end{tabular}

The student's results via role play method showed average score of $75 \%$ whereas didactic lectures showed the average percentage of $60 \%$.

The pretest result of Group A showed the mean of 12.15 and standard deviation (SD) of 6.7 whereas the post test result showed a mean of 15.2 with SD of 6.2. The surprise test result presented with a mean of 10.9 and SD of 6.2. The statistical analysis among these tests did not show any significant data. The comparisons of the pretest, posttest and surprise test results of Group A were statistically insignificant. The pretest, posttest and surprise test of Group B showed a mean of 11.7, 17.8 and 16.2 along with the SD of $6.97,5.85$ and 5.55 respectively. The one way ANOVA with post test showed a statistical significance between pretest and posttest results of Group B with $\mathrm{p}<0.01$. Overall comparisons of the pretest, posttest and surprise test results of Group B were statistically significant.

Comparison of pretest and posttest data among the groups showed statistically significant $(\mathrm{p}<0.05)$ result between pretest and posttest of Group A and Group B. Also $p<0.05$, was observed between the pretest and posttest result of Group B. The posttest result comparisons among groups were statistically insignificant.

The result of surprise test conducted after one month, was evaluated which was statistically significant between Group A and Group B $(\mathrm{p}<0.05)$. Comparison of posttest result of groups with the surprise test results presented significant statistics among posttest of Group B and surprise test of Group A, and Surprise test of Group A with Group B $(\mathrm{p}<0.05)$.

The absolute learning gain (ALG), Relative learning gain (RLG) and the class average normalize gain (g) was calculated and tabulated. As per Hake Criteria the class average learning gain achieved by role play method and didactic lecture both are of low to medium level ranging from 0.38 to 0.61 . The overall comparison of role play and the didactic 
Table 2: Total gain by role play and didactic lectures among Group Aand Group B

\begin{tabular}{|c|c|c|}
\hline Gain by the student & Role Play & Didactic lectures \\
Average Learning Gain & 40 & 25 \\
\hline Relative Learning Gain & 74 & 59 \\
\hline Class average normal gain (g) & 39.65 & 24.65 \\
\hline
\end{tabular}

Table 3: Overall comparison of role play and didactic lectures

\begin{tabular}{|c|c|c|c|c|c|c|c|c|}
\hline Group & Mean & SD & SEM & $\mathrm{MD}$ & & U & p-value & Remark \\
\hline Didactic lectures (20) & 10.9 & 6.24 & 1.39 & 10.5 & 7.98 & 13.8 & \multirow{2}{*}{$\mathrm{p}<0.05$} & \multirow{2}{*}{ Statistically significant } \\
\hline Role play (20) & 16.2 & 5.55 & 1.24 & 17.5 & 13.6 & 18.7 & & \\
\hline
\end{tabular}

\section{Discussion}

Through years, knowledge is imparted from one person to another person, by many ways, among which teaching is one such method. Teaching helps learning which involves observation, listening and understanding and imitating. The subject of teaching is variable; it may be spiritual, philosophical, mathematics, art or science. To whatever group they belonged the main aim of the teacher is to ensure that the students get maximum benefit out of his/her teaching.

In higher education system various important and different learning training methods are employed which has its own advantages and disadvantages (Table 4 and Fig. 1).
Role play, among all, was the best way of strengthening interactions by defining and implementing in several ways. Daly et al. (2009) suggested it to be a pedagogical method that raises the awareness of the effects and consequences. This was already mentioned by Alkin and Christie in 2002 , that the role play can provide the opportunity for student to student and student to faculty partnerships in the classroom where attitudes and feelings are in focus. In Mogra (2012) the statements were contradicted by stating that "Values and attitudes are visible to greater degree through body language than through verbal language. In activities, feelings, values and attitudes are visible and can be interpreted in words, and thus we can understand the context."

Table 4: Advantages and disadvantages of various teaching methods

\begin{tabular}{|c|c|c|}
\hline Teaching method & Advantage & Disadvantage \\
\hline Lecture & $\begin{array}{l}\text { Allows presentations of facts, information and concepts in a } \\
\text { short time. } \\
\text { Can be used with illiterate learners. } \\
\text { Various supportive materials like slides, posters etc. can be } \\
\text { used. } \\
\text { Large learners can be attended at a time. }\end{array}$ & $\begin{array}{l}\text { Speakers dominate. } \\
\text { Does not promote interactions. } \\
\text { Less focus by the participants. } \\
\text { Speed is controlled by the speaker. }\end{array}$ \\
\hline Group discussion & $\begin{array}{l}\text { Control learners pace, content and focus } \\
\text { Allows learners to express their knowledge and skills } \\
\text { It clarifies, reflect and reconfigure learner's experiences. } \\
\text { Promote a sense of belonging in a group. }\end{array}$ & $\begin{array}{c}\text { Time consuming. } \\
\text { Requires facilitations. } \\
\text { Problem due to dominant or } \\
\text { aggressive learners. } \\
\text { Learners might not be serious } \\
\text { Needs more space than lecture } \\
\text { Difficult to monitor many groups. }\end{array}$ \\
\hline Case study & $\begin{array}{c}\text { Simple } \\
\text { Can be used with illiterate learners. } \\
\text { Provides cognitive learning } \\
\text { Economical }\end{array}$ & $\begin{array}{l}\text { Difficult to find the appropriate case } \\
\text { study. } \\
\text { Case study maybe general and may } \\
\text { miss the specific issue. } \\
\text { Hypothetical. }\end{array}$ \\
\hline $\begin{array}{l}\text { Audio Visual } \\
\text { methods }\end{array}$ & $\begin{array}{c}\text { Simple } \\
\text { Important medium while dealing with illiterate learners. } \\
\text { Can be used singly, with/without sequence of pictures } \\
\text { Provides cognitive learning } \\
\text { Not Economical }\end{array}$ & $\begin{array}{l}\text { Difficult to find the appropriate } \\
\text { Pictures/videos and audios. } \\
\text { Audibility may/may not be clear. } \\
\text { Prepared items may be too idealistic. }\end{array}$ \\
\hline Role play & $\begin{array}{c}\text { Stimulating activity } \\
\text { Helps suppressed and low level learners to express their } \\
\text { feelings. } \\
\text { Simple and economic } \\
\text { Focus on problems with 'as if' situations. } \\
\text { It helps to present the complex issue in a simple way. } \\
\text { It does not need any materials or any advanced } \\
\text { preparations. } \\
\text { Helps improves knowledge, cognitive, interpersonal, } \\
\text { communication and social skills. }\end{array}$ & $\begin{array}{l}\text { Possibility of vitiate or impair } \\
\text { learning. } \\
\text { Learners get too involved in roles. } \\
\text { May loose objective of learning. } \\
\text { Participants may overact or distort the } \\
\text { roles }\end{array}$ \\
\hline
\end{tabular}




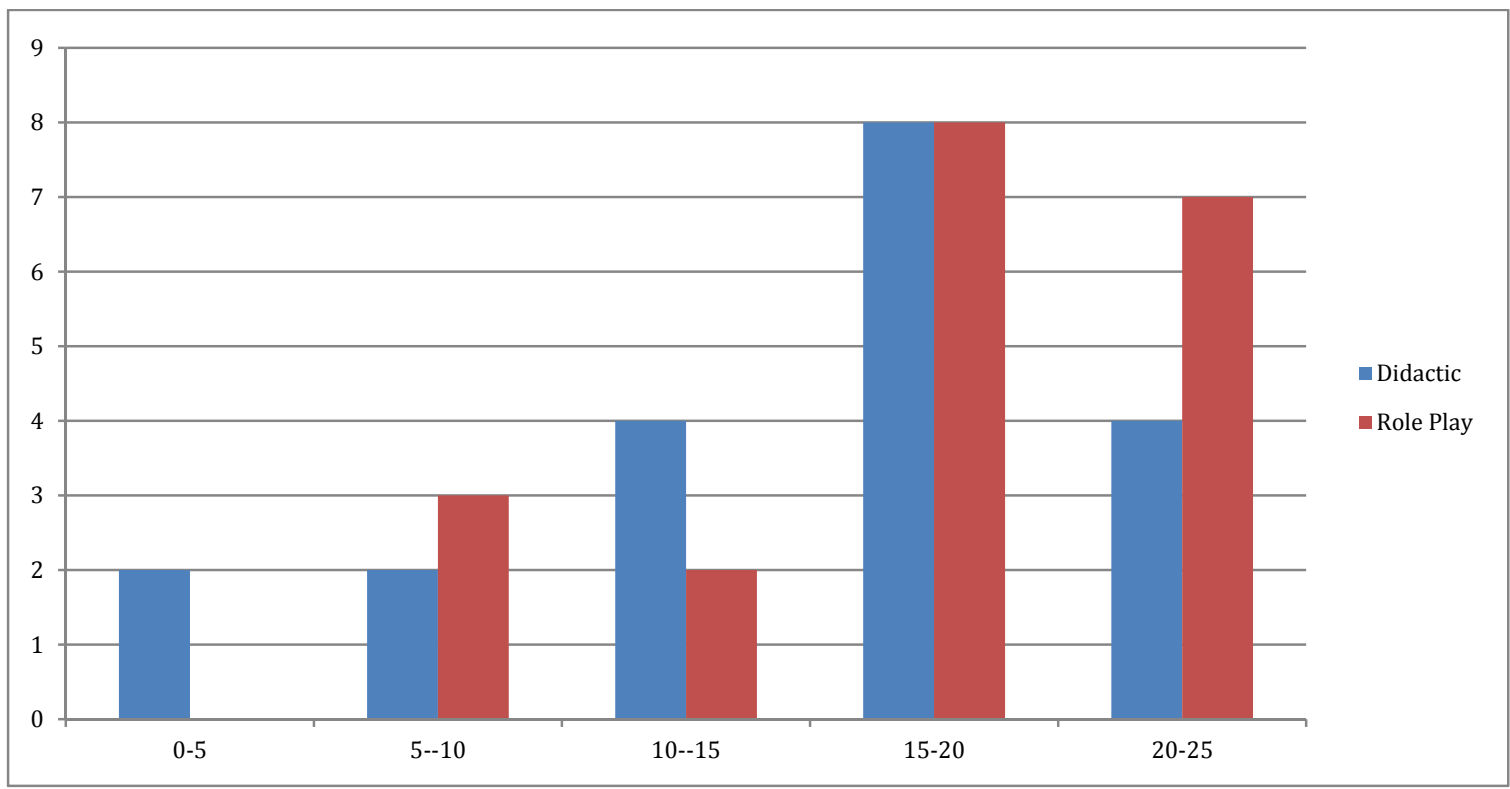

Fig. 1: Graph showing the distribution of scores in Group a (Didactic) and Group B (Role play)

Mogra (2012) mentioned that medical role play follow "Pendleton's Rules" which is very considerate way of ensuring that feedback is supportive rather than destructive. "Pendleton's Rules" are mentioned by David Pendleton in 1980s, as a major part in doctor -patient communication. Our experience says that a friendly and supportive environment needs to be created beforehand. This helped us to bring up low level, shy, nervous, timid and not interested students to participate actively and in a competitive way. Also, the active acceptance of this effective methodology by the students drew us to get the better result.

In the present study, we grouped students randomly into Group A and Group B for the didactic and role play teaching. The pretest was conducted in both the groups which showed $65 \%$ of students getting below average marks and only $35 \%$ students can get the average $(60 \%)$ or above average passing marks. 4-5 topics were taught through role play method to Group B students and through didactic lectures to Group A, after that, posttest was conducted for both the groups. The Post test results were surprising as Group B achieved more marks than Group A students. But the overall result of Group A and B were satisfactory. This could be due to the active participation of both groups of students in the subject irrespective of the method of teaching, but the role play teaching have opened or provided an open ground for the students to consolidate the new knowledge learned, and to emphasize their responsibility for their own education. In Group A $40 \%$ of students were below average which could be due to their optional participation in lecture and no interest in one way learning. The student might sit and listen to the teacher lecture in such a way that might have led to shallow knowledge or mock knowledge.

To assess the retained knowledge acquired through the role play method and didactic lecture, a surprise test was conducted after one month for both the groups. To our surprise, Group B students scored well with only $35 \%$ students getting below average marks whereas in Group A 60\% students presented below average marks. Thereby suggesting that in a lecture based formal education student retain knowledge until the exams and then they discard or forget the information. The role play method provided better interaction among students, better resources, possible ways to accomplish his/her tasks by solving the problems proposed by the teacher. This also helped students to hear an explanation from a colleague, examining his/her explanation and to assess the right or wrong answers and finally to discuss them with the teacher. Hence a powerful improvement in cognition, interpersonal skill development, knowledge, communication skills and a platform of making conceptual changes was provided by the role play.

Success of role play method also depends upon the skills of the teacher/tutor. It includes: 1) Listening - ability to listen sensibly and innovatively 2) Observation - ability to observe and monitor the groups work 3) Sensitivity -ability to see problems, understand the feelings, concepts, ethics and to focus on designed role play 4) Diagnosing - ability to define the problem 5) Supporting - ability to assist in mutual search for solutions 6) Challenging ability to challenge, disagree or to stop a process without being rude 7) Openness - ability to invite discussion and to receive feedback 8) Modeling ability to include a model in a group.

A role play needs to be set up carefully. It is difficult at first and complex hence it is wise to start small and give the activity clear structure. Initially, in our study, during practice the students stuck for words, phrases and sentence formation and the teacher acted as a walking dictionary to "feed in" appropriate language in the students. Later a chance to use real and natural language was given. Mistakes are common and there are many ways to correct it while using role play. Interrupting and correcting mistakes during the play maybe demotivating for the students. Hence two ways for corrections can be 
followed: 1) Self correction - this can be done by recording the whole play in audiocassette or on video which student can listen again and again and correct the errors. 2) Peer correction - this can be done by the colleague or fellow students by listening both the great bits of language and mistakes. Care must be taken to keep the peer correction an optimistic and gainful experience for all the involved participants (Liu and Ding, 2009).

Role play has long been used in the education in some areas and there is less published studies that have used this specific methodology to teach the medical-dental courses. The genuine work and originality of our research reveals possibility for improved teaching strategy in health science courses. This study encountered some limitations while teaching through role play method like time management, student gathering, noisier and deviation from the subject during discussion. Overall we experienced that teaching through role play was of a greater and better challenge and can be adopted as a prime learning method in higher education system.

\section{Conclusion}

Our result provided better result with involvement of all the students including nervous, timid and shy students, confidently to lead the role with better performance and improved skills such as cooperation and creativity. This marks us to conclude that role play is one of the valuable methods of teaching and learning and can be used as an effective teaching media in affective domain of learning outcomes.

\section{Acknowledgement}

We would like to acknowledge the Management and Dean of Buraydah Private Dental College for allowing us to carry out our work successfully.

\section{References}

Agboola Sogunro O (2004). Efficacy of role-playing pedagogy in training leaders: some reflections. Journal of Management Development, 23(4): 355371.

Alkin MC and Christie CA (2002). The use of roleplay in teaching evaluation. American Journal of Evaluation, 23(2): 209-218.

Chalakh S, Desai P, Devgade M and Pathak S (2015) To compare efficacy of role play versus didactic lectures in teaching legal procedure. Journal of Health Science Education, 2(1): 21-24.

Daly A, Grove SJ, Dorsch MJ and Fisk RP (2009). The impact of improvisation training on service employees in a European airline: a case study. European Journal of Marketing, 43(3/4): 459472.

Liu F and Ding Y (2009). Role-play in English language teaching. Asian Social Science, 5(10): 140-143.

Mogra I (2012). Role play in teacher education: Is there still a place for it?. Teacher Education Network Journal, 4(3): 4-15.

Nickerson S (2007). Role-play: An often misused active learning strategy. The Professional and Organizational Development Network in, 19(5):16-21

Rao D and Stupans I (2012). Exploring the potential of role play in higher education: development of a typology and teacher guidelines. Innovations in Education and Teaching International, 49(4): 427-436.

Westrup U and Planander A (2013). Role-play as a pedagogical method to prepare students for practice: The students' voice. Högre Utbildning, 3(3): 199-210.

Yardley-Matwiejczuk KM (1997). Role play: theory and practice. Sage, London. 